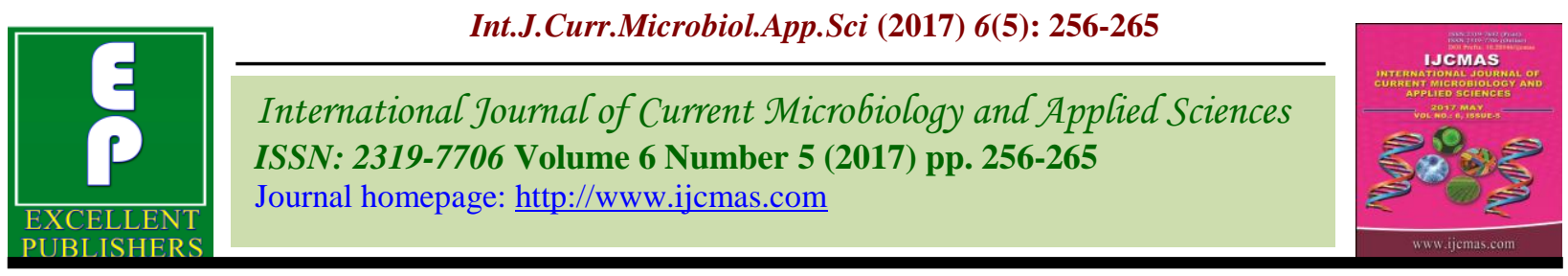

Original Research Article

https://doi.org/10.20546/ijcmas.2017.605.029

\title{
Evaluation of Organic Acid Producing Aspergillus niger Isolates for the Management of Fusarium Wilt of Chickpea
}

\author{
Swati Nayak and Vibha* \\ Department of Plant Pathology, Jawaharlal Nehru Krishi Vishwa Vidyalaya, \\ Jabalpur 482 004, Madhya Pradesh, India \\ *Corresponding author
}

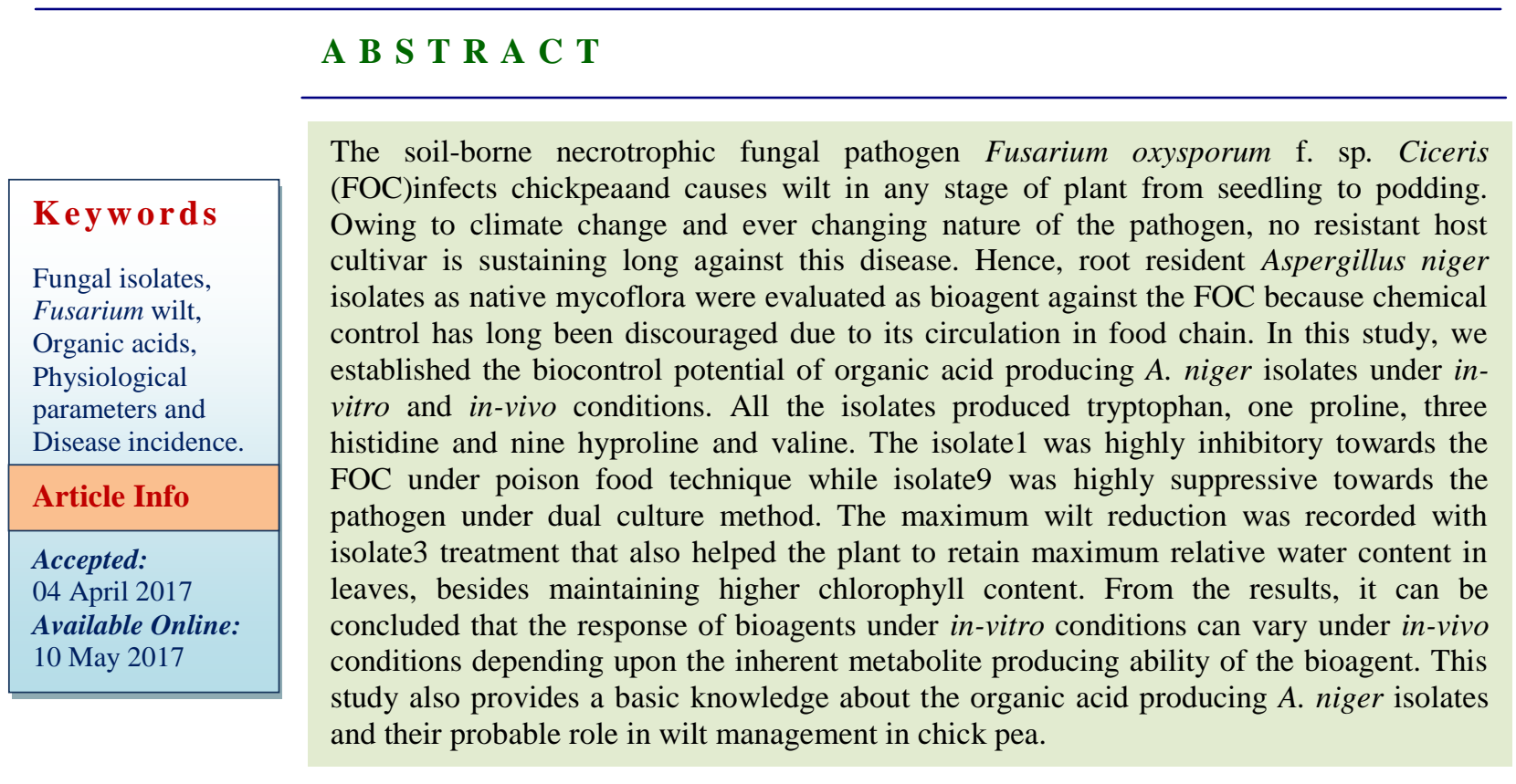

\section{Introduction}

Fusarium wilt is one of the major diseases of chickpea and at national level yield losses were reported to the tune of 60 per cent Singh et al., (2007). F. oxysporum f. sp. ciceris infects chickpea at seedling as well as at flowering and pod forming stage Grewal (1969), with more incidence at flowering and podding stages if the crop is subjected to sudden temperature rise and water stress Chaudhry et al., (2007). It is more prevalent in lower latitudes $\left(0-30^{\circ} \mathrm{N}\right)$ where growing season is relatively drier and warmer than in the higher latitudes $\left(30-40^{\circ} \mathrm{N}\right)$ Arunodhayam et al., (2014). On account of the complex environment, development of effective management strategies through chemicals, most likely to influence the biological activities of the system, is of great challenge. Utilization of resident mycoflora of any crop will be helpful in plant health management as these mycoflora produce several secondary metabolites that act against pathogenic microbes and also produce other plant growth promoting substances for crop growth. 
Aspergillus species have been reported as endophytes with antifungal activity Soltani and Hosseyni (2015) and able to produce several metabolites such as phenolic and bioactive flavonoid compounds that inhibit the growth of other pathogenic fungi. Bosah and co-workers (2010) recorded that the Aspergillus spp can inhibit the growth of pathogenic fungi Sclerotium rolfsii with inhibition of 73.12 to $88.35 \%$. The nine isolates of Aspergillus spp. were tested to control potato dry and pink rots caused by $F$. sambucinum under in vitro and in vivo conditions and were found to inhibit the mycelial growth of $F$. sambucinum by 27 to 68\% Daami-Remadi et al., (2006). Hence, the present study was under taken (1) to evaluate the inhibition potential of different organic acid producing isolates of bioagent under invitro conditions and (2) to establish their effect on physiological properties of crop apart from management of Fusarium wilt under in-vivo conditions.

\section{Materials and Methods}

\section{Collection of diseased specimens and purification of the pathogens}

Diseased chickpea plants exhibiting typical symptoms of wilt incidence levels were collected from the sick plots of AICRP on chickpea experimental field of Jawaharlal Nehru Krishi Vishwa Vidyalaya (22 $49^{\prime}-22^{0}$

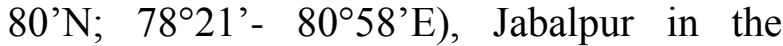
Central India during 2015-16. The pathogen was isolated and further purified through hyphal tip method and sub-cultured on potato dextrose agar (PDA) slants at $4{ }^{\circ} \mathrm{C}$ for further use. Dilution plate method was used to isolate the Aspergillus niger isolates from soil samples of chickpea plant showing different level of wilt symptom, on Rose Bengal Agar medium (RBA). Plates with RBA medium was added with $0.1 \mathrm{ml}\left(=10^{-4}\right)$ of suspension and incubated at $22 \pm 2{ }^{\circ} \mathrm{C}$ for 15 days. The colonies were transferred to test tubes containing PDA medium. The confirmations of non-aflatoxin producing or atoxigenic Aspergillus species have been done through growing them on Aspergillus differential media (Hi-media, Mumbai). The A. niger isolates were designated as AN1, AN2, AN3, AN4, AN5, AN6, AN7, AN8, AN9 and AN10 throughout the study.

\section{Evaluation of antagonistic potential of beneficial fungi in-vitro}

The antagonistic potentials of $A$. niger isolates were evaluated against the $F$. oxysporum through dual culture technique Denis and Webster (1971). A five mm disc of different fungal isolates were cut out from the seven days old culture and placed close to one end of the Petri-plate containing $20 \mathrm{ml}$ solidified PDA medium. At the opposite end, a similar disc from the culture of the pathogen FOC was placed simultaneously.

The Petri-plates were incubated at $25 \pm 2^{\circ} \mathrm{C}$ in a BOD incubator and the inhibition of the pathogen growth by the antagonistic fungi was measured after 48, 72 and $96 \mathrm{hrs}$ after incubation till both occupy the entire space of the plates.

Culture filtrate of AN isolates grown in PDA broth grown for 10 days were collected after passing it twice through Whatman filter paper No. 1. These filtrates were used to amend Petri-plates containing PDA at 5 per cent concentration and incubated at $25+2^{\circ} \mathrm{C}$ and observations were recorded after 48, 72, 96, 120, 144 and 168 hours, respectively; an unamended Petri-plate served as check (control).Each treatment was replicated thrice and the experiment was repeated twice.

The antagonism was measured on the basis of inhibition of the pathogen by the bio agent by the following formula: 
Inhibition $=$

Radial growth in control $(\mathrm{C}) \quad$ - Radial growth in the treatment $(\mathrm{T})$ Radial growth in control(C)

\section{Organic acid production}

\section{Preparation of $A$. niger isolates extract}

Culture filtrates of AN isolates grown in PDA broth grown for 10 days were collected after passing it twice through Whatman filter paper No. 1. These samples were homogenized and extracted with methanol and methanol: Chloroform (1:1). The extracted samples were centrifuged at $5000 \mathrm{rpm} \times 15 \mathrm{~min}$ and supernatant was collected. The excess solvents were removed by using rotary evaporator and the samples were lyophilized. Finally, the lyophilized samples were used for amino acid analysis through HPTLC. The five standards of amino acids were prepared at the concentration of $1 \mathrm{mg} / \mathrm{ml}$ in double distilled water and used for the further analysis.

\section{Preparation of the sample for HPTLC analysis}

The samples were dissolved in methanol at the concentration of $5 \mu 1 / \mathrm{ml}$ and centrifuged at $10,000 \mathrm{rpm} \times 1 \mathrm{~min}$ at $4^{\circ} \mathrm{C}$. The supernatant was filtered through Whatman filter paper No.1. The filtrates $(5 \mu 1$ of each) and the standard $(2 \mu \mathrm{l}$ each at a concentration of $1 \mathrm{ml} / \mathrm{ml}$ ) were coated on a pre-coated TLC aluminum silica gel $-60 \mathrm{~F} 254$ (Merck, Germany) $(10 \times 10 \mathrm{~cm})(20 \mathrm{~cm} \times 10 \mathrm{~cm})$. The TLC plates were developed with a solvent system consisting of n-butanol:ethyl acetate water: acetic acid (1:1:1:1). The developed plates were stained using $0.3 \%$ ninhydrin in n-butanol as spraying reagent and the plates were heated at $100^{\circ} \mathrm{C}$ for $1 \mathrm{~min}$. These plates were scanned, digitized and analyzed by using CAMAG software. The values of organic acids were expressed in percentage.
Assessment of antagonistic potential of $A$. niger isolates under in-vivo conditions

TheFOC inoculum was mass multiplied on sand + maize flour mix. The inoculum of fungus was produced on sand + maize flour mix (9:1), moistened with water and autoclave twice for 90 minutes on two consecutive days. One week old culture of fungi on potato dextrose agar medium was inoculated in sand + maize flour mix and incubated at room temperature for two weeks with repeated shaking at one week interval (Jimenez et al., 2001). Fungal inoculums prepared on sand + maize flour mix was used @ $15 \mathrm{gm}$ in $500 \mathrm{gm}$ of potting mix.Two sets of experiments with three replicates for each treatment were maintained. The experiment was done in two sets in two different polyhouses. Ten chickpea seeds were sown in each clean pot at the 2-3 cm deep in six pots for each strain of $A$. niger along with uninoculated control.

\section{Relative water content (RWC)}

Measurements of RWC Barrs and Weatherly (1962) were performed on leaves collected from chickpea plants. Individual leaves were first removed from the stem with tweezers and were weighed immediately (fresh mass, FM) to obtain minimum 0.5 gram from each sample. In order to obtain the turgid mass (TM), leaves were floated in distilled water inside a closed Petri dish. At the end of the inhibition period, leaf samples were placed in a pre-heated oven at $80{ }^{\circ} \mathrm{C}$ for $48 \mathrm{hr}$ to obtain the dry mass (DM). Values of FM, TM, and DM were used to calculate RWC, using the following equation:

$\operatorname{RWC}(\%)=[(\mathrm{FM}-\mathrm{DM}) /(\mathrm{TM}-\mathrm{DM})] \times 100$.

\section{Chlorophyll content index}

Chlorophyll Content Index was estimated using a portable chlorophyll meter Peng et al., 
(1992). Fully expanded leaves from three places of each plant indifferent treatments were selected for estimation of chlorophyll content index. The mean of triplicate readings taken using SPAD-502 (SPAD-502, Minolta, Japan) around the midpoint near the midrib of each sample were recorded for different treatments of chickpea leaves.

\section{Disease incidence}

The percent wilt incidence of each treatment was calculated by using following formulae.

Disease incidence $(\%)=$

No. of plants exhibiting wilt symptoms

X100

Total number of plants observed

\section{Results and Discussion}

Efficacy of Aspergillus niger against Fusairum oxysporum f. sp. ciceri under invitro and in-vivo conditions

All the tested isolates were significantly effective against the pathogen and markedly reduced the mycelial growth (Table 1). The inhibition of mycelia growth of FOC by different $A$. niger isolates varied between 12.95 and $29.97 \mathrm{~mm}$. The highest $(12.95 \mathrm{~mm})$ inhibition was recorded with the isolate 9 while the least $(29.97 \mathrm{~mm})$ with the isolate 3 . The isolate 5 and 10 were equally suppressive $(17.85 \mathrm{~mm}$ and $17.40 \mathrm{~mm})$ towards the pathogen. Although, there was an increase in growth of the pathogen at each time interval contrast was recorded with the isolates 8 and 9.The marked growth suppression of FOC was recorded at 48,72 and 96 hours with these two isolates.

It is evident from the results that all the isolates were effective in reducing the mycelial growth of pathogen except the isolate 9 (Table 2). Inhibitory effect of $A$. niger isolates varied among themselves but some isolates viz. $4(34.52 \mathrm{~mm}), 7(34.06 \mathrm{~mm})$, $3(36.99), \quad 8(36.30 \mathrm{~mm}), \quad 5(37.89) \quad$ and $6(37.73 \mathrm{~mm})$ were statistically at par with each other in suppressing the pathogen growth. Isolate $1(17.94 \mathrm{~mm})$ was highly suppressive towards FOC while the isolate $9(43.19 \mathrm{~mm})$ had promoted the growth of the pathogen. The A. niger isolate 1 was found to be highly suppressive at all the intervals of time. Growth suppression recorded in all the isolates up to $120 \mathrm{hrs}$ but culture filtrate of few isolates promoted the mycelial growth.

\section{Amino acids produced by $\boldsymbol{A}$. niger isolates}

The variation in amino acids production has been recorded among different isolates of $A$. niger. The maximum $(1.938 \%)$ tryptophane was produced by isolate1 whereas least $(0.023 \%)$ but identical by the isolates 3 and 5 . Except the isolate 3, none of the isolates produced proline. The presence of hyproline ranged between 1.701 and 0.283 percent in all the isolates except the isolate 9 whereas valine varied between 3.591 and 0.839 percent with exception to the isolate 10 (Table $3)$. The highest $(1.127 \%)$ amount of histidine was recorded in the isolate 3 while the least $(0.333 \%)$ in the isolate 1 . The valine ranged between 3.591 and 0.330 percent.

\section{Effect of Aspergillu sniger isolates on physiological parameters and wilt incidence in chick pea}

There was significant increase in relative water content (RWC) in chickpea leaves, inoculated with culture filtrate of different isolates of A. niger over the control (Table 4). The range varied between 42.99 and64.16 percent. The highest relative water content was recorded in isolate $3(64.16 \%)$ followed by isolate $2(59.34 \%)$. The RWC of the isolates 1, 5 and 8 were statistically at par 
with each other and were the next best to former isolate 4. Chlorophyll content of chickpea leaves ranged from 44.10 to 36.65 percent in uninoculated FOC while 30.21 to 40.0 percent in FOC inoculated (treated with culture filtrate of $A$. niger isolates) plants. The highest (44.10\%) chlorophyll content was recorded in control in FOC inoculated plants while least $(30.21 \%)$ was recorded in after FOC inoculation.

Disease incidence was markedly reduced by culture filtrate treatments. The minimum $(18.04 \%)$ was recorded in isolate 3 while the maximum (57.67\%) was recorded in the control. Similar treatment effect on wilt incidence was recorded with isolate 1, 2, 8 (29.99, 29.98 and $29.99 \%)$ and were next best to the isolate 3 in suppressing the disease.

All the tested isolates of $A$. niger inhibited the radial growth of the FOC in varying degrees of suppression but the isolates 9 and 8 out performed in inhibition under dual culture. The higher antagonistic activity of all the isolates of $A$. niger against the test fungi could be due to their fast mycelial growth and competition for nutrients in growing medium. Chakraborty and co-workers (2004) reported that the competition for nutrients, hyper parasitic behaviour and mechanical obstruction affects the efficiency of bioagents. Out of 10 isolates of $A$. niger, the culture filtrate of isolate 1 allowed the minimum $(17.94 \mathrm{~mm})$ growth of test pathogen while isolate $9(43.19 \mathrm{~mm})$ promoted the mycelia growth of the pathogen. FOC was not recovered with the time as it remained same at all the studied time intervals. This might be due to the difference in quality and quantity of the metabolite produced by the beneficial pathogen.

Table.1 Screening of Aspergillus niger isolates against Fusarum oxysporum f. sp. ciceri through dual culture method

\begin{tabular}{|lllll|}
\hline \multirow{2}{*}{ Fungal Isolates } & \multicolumn{2}{l}{ FOC (growth in mm) } & \\
\cline { 2 - 5 } 48hours & 72hours & 96hours & Mean \\
\hline AN1 & $19.33(10.96)$ & $27.43(16.19)$ & $38.99(39.58)$ & 28.59 \\
AN2 & $19.70(11.35)$ & $24.22(13.06)$ & $32.91(29.54)$ & 25.61 \\
AN3 & $20.12(11.82)$ & $29.22(18.24)$ & $40.58(42.34)$ & 29.97 \\
AN4 & $18.30(9.88)$ & $19.54(8.40)$ & $22.78(15.00)$ & 20.21 \\
AN5 & $16.10(7.69)$ & $16.28(6.11)$ & $21.16(13.08)$ & 17.85 \\
AN6 & $20.03(17.69)$ & $28.54(11.72)$ & $39.46(40.37)$ & 29.34 \\
AN7 & $11.24(3.75)$ & $29.44(24.17)$ & $31.41(27.00)$ & 24.03 \\
AN8 & $17.18(8.71)$ & $15.45(5.56)$ & $9.63(2.82)$ & 14.09 \\
AN9 & $17.12(8.65)$ & $14.98(5.36)$ & $6.15(1.40)$ & 12.95 \\
AN10 & $17.11(8.66)$ & $17.05(6.58)$ & $18.42(10.04)$ & 17.40 \\
Control & $22.8(15.00)$ & $33.2(30.00)$ & $42.13(45.00)$ & 32.71 \\
Mean & 18.0 & 23.1 & 30.80 & \\
\hline C V & 2.41 & & & \\
Fungus CD $(\mathrm{P} \leq 0.05)$ & 0.54 & & & \\
Hours CD $(\mathrm{P} \leq 0.05)$ & 0.28 & & & \\
Fungus $x$ Hours & 0.94 & & & \\
\hline
\end{tabular}

The values in the parenthesis are original values that are arcsine transformed 
Table.2 Evaluation of different isolates of Aspergillus niger against mycelial growth of Fusarium oxysporum f. sp ciceri

\begin{tabular}{|c|c|c|c|c|c|c|c|}
\hline \multirow{2}{*}{ Fungal Isolates } & \multicolumn{7}{|c|}{ Pathogen (growth in $\mathbf{m m}$ ) } \\
\hline & 48hours & 72hours & 96hours & 120hours & 144hours & 168hours & Mean \\
\hline AN1 & $17.94(9.50)$ & 17.94(9.50) & $17.94(9.50)$ & 17.94(9.50) & $17.94(9.50)$ & 17.94(9.50) & 17.94 \\
\hline AN2 & $24.09(16.67)$ & $28.19(22.33)$ & $34.24(31.67)$ & $41.55(44.00)$ & $51.65(61.50)$ & $55.14(67.33)$ & 39.14 \\
\hline AN3 & $23.57(16.00)$ & $27.03(20.67)$ & $33.41(30.33)$ & $39.23(40.00)$ & $48.35(55.83)$ & $50.38(59.33)$ & 36.99 \\
\hline AN4 & $20.67(12.50)$ & $27.26(21.00)$ & $31.08(26.67)$ & $36.57(35.50)$ & $44.61(49.33)$ & $46.91(53.33)$ & 34.52 \\
\hline AN5 & 26.07(19.33) & $28.88(23.33)$ & $34.03(31.33)$ & $38.93(39.50)$ & $47.77(54.83)$ & $51.65(61.50)$ & 37.89 \\
\hline AN6 & $25.08(18.00)$ & $28.19(22.33)$ & $34.03(31.33)$ & $39.22(40.00)$ & $46.53(52.67)$ & $53.33(64.33)$ & 37.73 \\
\hline AN7 & $19.88(18.00)$ & $23.55(16.00)$ & $33.62(30.67)$ & $39.62(40.67)$ & $42.70(46.00)$ & $45.00(50.00)$ & 34.06 \\
\hline AN8 & $21.26(11.67)$ & $24.59(17.33)$ & $35.26(33.33)$ & $41.55(44.00)$ & $45.76(51.33)$ & $49.41(57.67)$ & 36.30 \\
\hline AN9 & $28.52(13.17)$ & $31.60(27.47)$ & $38.44(38.67)$ & $45.86(51.50)$ & $55.14(67.33)$ & $59.56(74.33)$ & 43.19 \\
\hline AN10 & $26.89(22.80)$ & $30.15(25.33)$ & $35.66(34.00)$ & $38.44(38.67)$ & $42.99(46.50)$ & $58.71(73.00)$ & 38.81 \\
\hline Control & $22.81(15.00)$ & $33.20(30.00)$ & $42.13(45.00)$ & $49.60(58.00)$ & $51.94(62.00)$ & $53.71(64.96)$ & 42.23 \\
\hline Mean & 23.34 & 27.33 & 33.62 & 38.95 & 45.03 & 49.25 & \\
\hline $\mathrm{C} \mathrm{V}$ & 2.71 & & & & & & \\
\hline FungusCD $(\mathrm{P} \leq 0.05)$ & 0.64 & & & & & & \\
\hline HoursCD $(\mathrm{P} \leq 0.05)$ & 0.47 & & & & & & \\
\hline Fungus x Hours & 1.57 & & & & & & \\
\hline
\end{tabular}


Table.3 Production of different organic acids by Aspergillus niger isolates

\begin{tabular}{|l|c|c|c|c|c|}
\hline \multicolumn{7}{|c|}{ Amino acids (\%) } \\
\hline A. niger isolates & Tryptophane & Proline & Hyproline & Histidine & Valine \\
\hline Isolate1 & 1.938 & - & 0.635 & 0.335 & 0.633 \\
\hline Isolate2 & 0.401 & - & 0.714 & - & 2.158 \\
\hline Isolate3 & 0.023 & 2.230 & 0.874 & 1.127 & 0.330 \\
\hline Isolate4 & 0.449 & - & 0.409 & - & 0.839 \\
\hline Isolate5 & 0.023 & - & 0.283 & - & 1.114 \\
\hline Isolate6 & 0.082 & - & 0.618 & - & 1.262 \\
\hline Isolate7 & 0.033 & - & 0.343 & - & 2.255 \\
\hline Isolate8 & 0.366 & - & 1.701 & 0.721 & 2.124 \\
\hline Isolate9 & 0.318 & - & - & - & 3.591 \\
\hline Isolate10 & 0.321 & - & 1.031 & - & - \\
\hline
\end{tabular}

Table.4 Effect of culture filtrate of different Aspergillus niger isolates on physiological parameters and disease incidence on chickpea

\begin{tabular}{|c|c|c|c|c|}
\hline \multirow{2}{*}{$\begin{array}{l}\text { Aspergillusniger } \\
\text { isolates }\end{array}$} & \multirow{2}{*}{$\begin{array}{l}\text { Relative water } \\
\text { content }(\%)\end{array}$} & \multicolumn{2}{|c|}{$\begin{array}{l}\text { Chlorophyll Content } \\
\text { (SPAD 502) }\end{array}$} & \multirow{2}{*}{$\begin{array}{l}\text { Wilt incidence } \\
(\%)\end{array}$} \\
\hline & & $\begin{array}{l}\text { Before } \\
\text { Inoculation }\end{array}$ & After Inoculation & \\
\hline AN1 & $58.71(74.00)$ & $42.78(46.13)$ & $39.01(39.63)$ & $29.99(25.00)$ \\
\hline AN2 & $59.34(75.00)$ & $36.65(35.63)$ & $32.17(28.37)$ & $29.98(25.00)$ \\
\hline AN3 & $64.16(79.20)$ & $41.66(44.20)$ & $39.52(40.50)$ & $18.04(10.00)$ \\
\hline AN4 & $54.33(66.00)$ & $40.43(42.07)$ & $34.84(38.33)$ & $40.85(42.80)$ \\
\hline AN5 & $58.27(74.00)$ & $43.28(47.00)$ & $39.03(39.67)$ & $31.51(27.30)$ \\
\hline AN6 & $51.94(62.00)$ & $37.66(37.33)$ & $35.86(34.33)$ & $45.00(50.00)$ \\
\hline AN7 & $52.53(64.00)$ & $42.47(45.60)$ & $40.00(41.33)$ & $45.00(50.00)$ \\
\hline AN8 & $58.70(74.00)$ & $42.13(45.00)$ & $39.11(39.80)$ & $29.99(25.00)$ \\
\hline AN9 & $56.79(69.00)$ & $38.46(38.70)$ & $37.40(36.90)$ & $32.28(28.50)$ \\
\hline AN10 & $55.55(67.00)$ & $39.71(40.83)$ & $38.88(39.40)$ & $39.23(40.00)$ \\
\hline Control & $42.99(46.50)$ & $44.10(48.43)$ & $30.21(25.00)$ & $57.67(71.40)$ \\
\hline $\mathrm{CV}$ & 1.94 & 1.60 & 2.29 & 4.85 \\
\hline $\mathrm{CD}(\mathrm{P} \leq 0.05)$ & 1.84 & 1.11 & 1.44 & 3.00 \\
\hline
\end{tabular}

The value in the paranthesis is the original values

Almassi et al., (1994) have reported some secondary metabolites viz., 2-carboxymethyl 3-n-hexyl maleic acid andydride, 2methythylene-3-(6-hydroxy hexyl) butanedioic acid which they isolated from an unspecified isolate of $A$. niger have growth promoting effect. The difference in nature, quantity, and quality of the inhibitory substance produced by the beneficial fungi has been reported by several workes (Barkat et al., 2013; Shafiquzzaman, 2009). Mandol (1998) has proved that A. niger AN27 has mycoparasitic action against several important soil borne pathogens viz., Fusarium oxysporum ciceri (FOC), Macrophomina phaseolina, Phythium aphanidermatum and 
Rhizactonia solani. The principal antifungal compound produced by this strain was Trans and cis-4(3acetoxy -6- methoxy-2-hydroxy phenyl)-2-methoxy butanolite Angappan et al., (1996).

The minimum chlorophyll content index and relative water content was recorded in pot treated with FOC in control while higher in others, treated with culture filtrate of $A$. niger isolates. Such result may be attributed to potential of beneficial mycoflora to overcome the biotic stress by preventing the pathogenic fungi to colonies the root system and further clogging of xylem vessel to create water stress. The water stress resulted in a significant decrease (55\%) in chlorophyll content and the leaf relative water content was recorded by Kirnak et al., (2001). Although the minimum wilt incidence was recorded with $A$. niger isolate $3(18.04 \%)$ but isolate1, 2 and 8 equally (29.99\%) suppressed the disease and were the next best to the isolate 3 against the FOC. Such suppression in disease could be due the production of amino acids like proline and histidine by the A. niger isolates that signal the plant cell to initiate the defense regulatory system and also through providing cytoprotection to plant cell. Proline is known to possess a potent cell-protective function by ameliorating oxidative stress as many biotic (pathogens) and abiotic (e.g., UV and high and low temperatures) stresses involve oxidative stress and PCD. The ability of proline to quench ROS and function as a cytoprotectant may have important implications beyond those observed in $C$. trifolii as evidenced by the ability of proline to protect yeast and its association with stress protection in plants Delauney and Verma (1993). Besides, nitrogen uptake is very important for plant growth which is available in the soil as ammonium and nitrate. Ammonium, nitrate, and amino acids are absorbed by the extraradical mycelium of fungi that is generally taken up in the form of ammonium through a protein transporter named AMT1 (fungal origin). Among amino acids, arginine is typically involved in the translocation of nitrogen. Within the extraradical mycelium, ammonium combines with glutamate to form glutamine due to the activity of glutamine synthetase. After glutamine synthesis, arginine synthesis takes place with help of the enzyme arginosuccinate synthetase and arginine is the final product utilized by plants in case of AM fungi Barman et al., (2016). Although some other interesting roles were reported for a few series of fungal histidinekinase, but they currently appear species-specific including melanin production, adaptation to hypoxia, regulation of secondary metabolism, and biofilm formation Defosse et al., (2015). Bashar and Rai (1994) observed that A. flavus and $A$. niger amended in soil suppressed the growth of FOC and exhibited strong fungistatic activity against germination of conidia of test pathogen. Plants pre-treated with FOC followed by beneficial fungus appeared healthy with no wilting or root rot symptoms for more than 10 days. Wilt can be observed within 25 days of sowing into infected soil Nene et al., (1978). According to Heydari and Pessarakli (2010) different modes of action of bio control active micro-organism in controlling fungal plant disease include hyper-parasitism, predation, antibiosis, cross protection, competition for site and nutrient and induced resistance.

Based on our results, chickpea root system contains biological diversity even under stress to counter the effect of more vulnerable plant disease, such as Fusarium wilt. Immediate actions through metabolically active bioagents are necessary to restore the balance of the soil ecosystem and plant health.

\section{References}

Almassi, F., E.L. Ghisalberti and Rowland C.Y. 1994. Alkylcitrate-derived 
metabolites from Aspergillus niger. $J$. Nat. Prod., 57: 833-836.

Angappan, K., P.Dureja and Sen, B. 1996. Multiprong action of biocontrol agent, Aspergillus Niger (AN27). In: proceeding of $2^{\text {nd }}$ International crop science congress on crop productivity and sustainability-shaping the future, Society of Pesticide Science, New Delhi, India. pp.10,30,301.

Arunodhayam, K., N.P.E. Reddy and Madhuri, V. 2014. Pathogenicity and management of Fusarium wilt of chickpea, Cicer arietinum L. - A review. Curr. Biotica, 7(4): 343-358.

Bahar, M.A., and Rai, B. 1994. Antagonistic potential of root-region microflora of chickpea against Fusarium oxysporumf.spciceri. Bangl. J. Bot., 23(1): 13-19.

Barakat, F.M., N.M. AbadaAbou-Zeid and Gammal, Y.H.E. (2013). Effect of volatile and non-volatile compounds of Trichoderma spp. on Botrytis fabae the causative agent of faba bean chocolate spot. World. J. Agri. Res., 1(3): 42-50.

Barman, J., A. Samanta, B. Saha and Datta S. 2016. Mycorriza: the oldest association between plant and fungi. Resonance, Pp. 1093-1104.hptt./www.ias.ac.in

Barrs, H.D., and Weatherley, P.E. 1962.A reexamination of the relative turgidity technique for estimating water deficits in leaves. Aust. J. Bio. Sci., (15): 413 428.

Bosah, O., C.A. Igeleke and Omorusi, V.I. 2010.In vitro microbial control of pathogenic Sclerotium rolfsii. Int. J. Agr. Bio., 12: 474-476.

Chakraborty, M.R., S. Dutta, S. Ojha and Chatterjee N.C. 2004. Antagonistic potential of biocontrol agents against Botryodiplodia theobromae causing die-back of bottle brush (Callistemon citrinus). Acta Botanica Hungarica, 46: 279-286.
Chaudhry, M.A., M.B. Ilyas, F. Muhammad and Ghazanfar M.U. 2007. Sources of resistance in chickpea germplasm against Fusarium wilt. Mycopathogia, 5: $17-21$.

Daami-Remadi, M., H. Jabnoun-Khiareddine, F. Ayed, K. Hibarand Znaidi, I.E.A. 2006. In vitro and in vivo evaluation of individually compost fungi for potato Fusarium dry rot biocontrol. J. Biosci., 6: 572-580.

Defosse, T.A., A. Sharma, A.K. Mondal, T. Duge de Bernonville, J.P. Latge and Calderone, R. 2015. Hybrid histidine kinases in pathogenic fungi. J. Mol. Microbiol., 95: 914-924.

Delauney, A.J., and Verma, D.P.S. 1993. Proline biosynthesis and osmoregulation in plants. Plant. J., 4: 215-223.

Dennis, C., and Webster, J. 1971. Antagonism properties of species groups of Trichoderma, III. Hyphal interaction. T. Brit. Mycol. Soc., 57: 363-369.

Grewal, J.S. 1969. Important fungal disease of Cicer arietinum in India. In: Pulse Improvement Project Seminar, Karaj Agricultural College, University of Tehran and USDA. 7-9 January, pp 3540.

Heydari, A., and Pessarakii, M.A.R. 2010. Review on biological control of fungal plant pathogens using microbial antagonists. J. Biol. Sci., 10: 273-290.

Jimenez-Gasco, M.M., E. Perez-Artes and Jimenez-Diaz, R.M. 2001. Identification of pathogenic races $0,1 \mathrm{~B} / \mathrm{C}, 5$, and 6 of Foc with Random Amplified Polymorphic DNA (RAPD). Europ. J. Plant Pathol., 107: 237-248.

Kirnak, H., C. Kaya, I. Tas and Higgs, D. 2001. The influence of water deficit on vegetative growth, physiology, fruit yield and quality in eggplants. Bangladesh J. Plant Pathol., 27(3/4): 34-46. 
Mandol, G., 1998. In-vitro evaluation of Aspergillusniger AN27 against soil borne pathogens and field testing against Macrophaseolina phaseolina on potato, India. Ph.D. Thesis, Indian Agriculture Research Institute, New Delhi, India.

Nene, Y.L., M.P. Haware and Reddy, M.V. 1978. Diagnosis of some wilt-like disorders of chickpea (Cicer arietinum). ICRISAT Information Bulletin, No 3.

Peng, S., F.Garcia, R.Laza and Cassman K.G. 1992. Leaf thickness affects the estimation of leaf using a chlorophyll meter. Int. Rice Res. Newsl., 17(16): 19-
20.

Shafiquzzaman, S., U.K. Yusuf, K. Hossain and Jahan, S. 2009. In vitro studies on the potential Trichoderma harzianum for antagonistic properties against Ganodermaboninense. J. Food. Agric. Environ., 7(3): 970-976.

Singh, G., W.Chen, D.Rubiales, K.Moore, Y.R. Sharma and Gan, Y. 2007. Diseases and their management. In: Chickpea Breeding and Management (Eds.) R. Yadav, W. Chen and Y.R. Sharma. CAB International, Pp. 497519.

\section{How to cite this article:}

Swati Nayak and Vibha. 2017. Evaluation of Organic Acid Producing Aspergillus niger Isolates for the Management of Fusarium Wilt of Chickpea. Int.J.Curr.Microbiol.App.Sci. 6(5): 256-265. doi: http://dx.doi.org/10.20546/ijcmas.2017.605.029 